\title{
I will see it done: Metonymic extensions of the verb see in English
}

\begin{abstract}
English verbs of perception appear to be significant generators of divergent polysemous senses. The aim of this paper is to propose a dictionary study of the verb see. It appears that many semantic extensions of the term are metonymic in nature, because they are motivated by metonymic shifts within specific State-of-Affairs Scenarios (SASs). Three distinct dictionary sources are consulted in order to identify different metonymic extensions of the verb see. The majority of the database samples appear to belong to the PART FOR WHOLE propositional metonymy category (a stage of SAS for SAS). The conceptual link between seeing and intellectual comprehension is complex and appears to require the discussion of metonymy-metaphor interaction for its fuller explanation. The analysis is followed by conclusions drawn from the database study, as well as suggestions for future research in the field of metonymic extensions of English terms of visual perception.
\end{abstract}

Keywords: propositional metonymy, State-of-Affairs Scenarios, metonymy-metaphor interaction, visual perception, see.

\section{A brief outline of the propositional metonymy theory}

The theory of metonymy in contemporary linguistics has come a long way from the days of rising interest in the topic (Lakoff \& Johnson 1980; Norrick 1981; Nunberg 1978). This has occurred through a primary focus on the referential aspects of metonymies (Croft 1993; Kövecses \& Radden 1998; Radden \& Kövecses 1999) and also a more inclusive look at the issue, encompassing types of formal, propositional, and illocutionary metonymy (Bierwiaczonek 2001, 2007, 2013; Hernández 2007; Panther \& Thornburg 1999, 2003b, 2003c; Ruiz de Mendoza \& Otal Campo 2002). In his discussion of metonymy, Bierwiaczonek (2013: 16) adopts a modified definition of Kövecses and Radden (1998: 39) to refer to metonymy as "a cognitive process in which one conceptual entity, the vehicle, provides mental access to another conceptual entity, the target, associated with it within the same single integrated conceptualisation.” This definition warrants a significantly broad understanding of the term, which encompasses, besides referential metonymy, different types of formal, propositional, and illocutionary metonymy.

1 Address for correspondence: Institute of English, University of Silesia, ul. Gen. Stefana Grota-Roweckiego 5,41-205 Sosnowiec, Poland. E-mail: lukasz.matusz@us.edu.pl 
The focus of the present paper is on propositional metonymy, as presented by Panther and Thornburg (1999, 2003a, 2005, 2007) and modified by Bierwiaczonek (2013). Bierwiaczonek (2013: 24-26) disregards Panther and Thornburg's distinction between referential and predicational types within the propositional metonymy category. Instead, he proposes that propositional metonymy can be divided into propositional sentential metonymy and predicative metonymy. Thus, in Bierwiaczonek's (2013: 156) definition:

Propositional metonymy is a metonymy in which the whole propositional content $p$ of a sentence $S$ is used to access either the whole ICM, or another propositional content $q$ within the same ICM. If the proposition serving as the target is accessed by a sentence whose propositional meaning is completely different from the target (i.e. its subject and predicate are different), then the metonymy may be called sentential. If the propositional metonymy is limited to the predicate, the metonymy is referred to as predicative.

A significant example of propositional (predicative) metonymy in action was presented by Lakoff (1987: 78), who reported on the way in which the speakers of Ojibwa, a Native American language of central Canada, refer to the activity of travelling. Upon being asked how they arrived at a certain destination, Ojibwa speakers would typically reply with the following English equivalents:

1. I started to come.

2. I stepped into a canoe.

3. I got into a car.

What follows is that Ojibwa speakers have a way of conventionally using a particular stage of the travelling script, namely the stage of Embarkation, to talk about the scenario as a whole. The particular cognitive construct underlying this kind of metonymic transfer consists of five stages representing the prototypical succession of events for moving towards a destination in a vehicle:

Table 1. The Travelling Scenario (Lakoff 1987: 78)

\begin{tabular}{|l|l|l|}
\hline 1 & Precondition & You have (or have access to) the vehicle. \\
\hline 2 & Embarkation & You get into the vehicle and start it up. \\
\hline 3 & Centre & You drive (row, fly, etc.) to your destination. \\
\hline 4 & Finish & You park and get out. \\
\hline 5 & End point & You are at your destination. \\
\hline
\end{tabular}


Ojibwa speakers using the stage of Embarkation to talk about travelling as a whole represents a predicative metonymy in which part of the travelling script is used to access the whole scenario (PART FOR WHOLE metonymy). Lakoff (1987: 78) notes also that this kind of metonymy is by no means limited to Ojibwa. Speakers of English, for instance, often use similar predicative metonymies in which different stages of the script refer to travelling as a whole:

4. I have a car. (Precondition)

5. I borrowed my brother's car. (Precondition)

6. I hopped on a bus. (Embarkation)

7. I just stuck out my thumb. (Embarkation)

8. I drove. (Centre)

Bierwiaczonek (2013: 158) notes in this context that the Travelling Scenario in English may also be accessed by more conceptually distant sentential metonymies, as in (9) and (10), below:

9. My brother gave me a lift. (Precondition)

10. My sister had lent me her car. (Precondition)

The script presented in Table 1, above, is a particular realisation of what Panther and Thornburg (1999: 337) refer to as a State-of-Affairs Scenario (SAS), that is, a general script for propositional contents describing an existing (actual) state of affairs. A SAS is divided into four stages developing in time, each one possessing its specific elements, as demonstrated in Table 2:

Table 2. State-of-Affairs Scenario (Panther \& Thornburg 1999: 337)

\begin{tabular}{|l|l|l|}
\hline 1. & The Before & $\begin{array}{l}\text { Necessary preconditions: motivations, potentialities, capabilities, } \\
\text { abilities, dispositions, etc., which can bring about the State of Affairs }\end{array}$ \\
\hline 2. & The Core & The existing, true State of Affairs \\
\hline 3. & The Effects & $\begin{array}{l}\text { Necessary consequences immediately following from the State } \\
\text { of Affairs }\end{array}$ \\
\hline 4. & The After & Non-necessary consequences of the State of Affairs \\
\hline
\end{tabular}

In the forthcoming sections, I adopt Panther and Thornburg's (1999) framework of SASs in order to propose specific scripts motivating different propositional metonymies of the verb see in English. 


\section{Methodology}

The aim of this paper is to propose a dictionary analysis of the verb see in English in order to identify different metonymically motivated extensions of the term. For this aim, I intend to focus primarily on the framework of propositional metonymy, as defined by Bierwiaczonek (2013: 156). Different propositional metonymies of the verb are presented by means of Panther and Thornburg's (1999: 337) SASs in their various realisations. The subsequent study is based on a database analysis involving three dictionary sources: Collins COBUILD Advanced Learner's English Dictionary (CCALED), Longman Dictionary of Contemporary English (LDCE), and The New Oxford Dictionary of English (TNODE). Admittedly, focusing the analysis solely on dictionary sources may seem controversial because it conceivably poses the risk of providing less representative results than real-life corpora-based data. However, the main goal of this analysis is to look at specific senses of the verb see in order to propose a framework on which future, possibly more representative research may be constructed. I believe that a short dictionary analysis may be sufficient for this purpose.

In order to analyse different senses of the verb see, appropriate dictionary entries have been considered and representative examples are provided with their dictionary sources in parentheses. The starting point of the analysis should conceivably be to identify the basic, non-metonymic sense of the verb. LDCE defines the primary meaning of see as to "notice/examine something using your eyes." According to CCALED, "when you see something, you notice it using your eyes." Consider the following examples from the dictionary database:

\section{Can you see the Houses of Parliament from here? (LDCE)}

12. I saw a man making his way towards me. (CCALED)

13. You can't see colours at night. (CCALED)

The primary meaning of see appears to be, thus, the one of visual perception of the object of seeing. An adequate description of human visual modality and its linguistic representation goes well beyond the scope of this paper. Suffice it to say here that in visual perception, an individual experiences immediate and direct sensory data, irrespective of the intentional act of the individual's will (Miller \& Johnson-Laird 1976: 586). Thus, in the remaining part of this article, whenever I make a reference to the act of seeing, I refer to (unless otherwise specified) the act of an involuntary perception of visual data by a sentient human individual.

In the forthcoming sections, I aim to distinguish different metonymic extensions of see by analysing dictionary entries for the term in order to establish which senses of the verb are underlain by possible propositional metonymic transfers. For this aim, 
I refer to SASs as presented by Panther and Thornburg (1999). The act of seeing in different SASs presented below appears to be a salient stage of its respective scenarios. Therefore, I expect to find cases in which the act of visual perception is a part of a larger SAS (PART FOR WHOLE metonymy). Selected SASs, serving as the basis for the examples, will be presented, as well. It is conceivable that for some database examples, the analysis based on metonymic shifts within SASs will not be sufficient and that for a fuller understanding of the issues at hand, the role of metonymy-metaphor interaction should also be considered.

In the forthcoming analysis, I am going to focus on a number of polysemy patterns of see as they are presented and exemplified in the dictionary sources. Therefore, this paper does not presume to provide the full picture of how metonymic processes operate in different senses of the verb. Also, the limited scope of this paper precludes any reasonable representation of a full polysemy network for English expressions of visual perception. Despite these shortcomings, I hope that the forthcoming analysis provides a reasonably informative and sufficiently representative account of certain metonymic patterns of the verb see on which future study of the issues at hand may be based.

\section{Part for whole metonymic patterns of see}

In his discussion of the metonymy-motivated polysemy of verbs, Bierwiaczonek (2013: 201-202) provides numerous examples in which the act of seeing is a central component of a more complex script (PART FOR WHOLE metonymy):

14. We are going to see 'Hamlet' tonight.

- seeing aS PART OF WATCHING FOR WATCHING

15. I'm seeing the doctor tomorrow afternoon.

- seeing AS PART OF VISIT FOR VISITING

16. Tom is seeing a client.

- seeing AS PART OF MEETING FOR MEETING

17. They've been seeing a lot of each other.

- seeing aS PART OF SPENDING TIME WITH SOMEONE FOR SPENDING TIME WITH THAT PERSON

18. Mary is seeing John now.

- PART OF HAVING A ROMANTIC RELATIONSHIP FOR HAVING A ROMANTIC RELATIONSHIP

19. It's up to you to see if the job is done properly.

- PART OF CHECKING AND CONTROLLING FOR CHECKING AND CONTROLLING

The categories proposed by Bierwiaczonek are corroborated by numerous examples from the dictionary database. Consider, for instance, the following: 
20. We're going to see 'Romeo and Juliet' tonight. (LDCE)

21. He had been to see the semi-final of the FA Cup. (CCALED)

- seeing as PART OF WATCHING FOR WATCHING

22. She was seen by a doctor but didn't need hospital treatment. (LDCE)

23. You need to see a doctor. (CCALED)

- seeing aS PART OF VISIT FOR VISITING

24. Mr. Thomas is seeing a client at 2:30. (LDCE)

25. You may need to see a solicitor. (TNODE)

- seeing as PART OF MEETING FOR MEETING

26. They have been seeing a lot of each other. (LDCE)

27. They've seen more of each other since Dan moved to London. (LDCE)

- seeing aS PART OF SPENDING TIME WITH SOMEONE FOR SPENDING TIME WITH THAT PERSON

28. Is she seeing anyone at the moment? (LDCE)

29. My husband was still seeing her and was having an affair with her. (CCALED)

- PART OF HAVING A ROMANTIC RELATIONSHIP FOR HAVING A ROMANTIC RELATIONSHIP

30. Please see that the lights are switched off. (LDCE)

31. See that you take care of him. (CCALED)

- PART OF CHECKING AND CONTROLLING FOR CHECKING AND CONTROLLING

In sentences (20) to (31), the act of seeing is metonymically used to access its respective scenario as a whole. Thus, I consider (20) to (31) to be examples of PART FOR WHOLE propositional metonymy. Each of the above categories requires a specific SAS in order to illustrate the metonymic transfer. Consider, by way of illustration, the following Watching Scenario underlying examples (14), (20), and (21):

Table 3. The Watching Scenario

\begin{tabular}{|l|l|}
\hline \multicolumn{2}{|c|}{ The Watching Scenario } \\
\hline \multirow{3}{*}{ 1. The Before } & $\begin{array}{l}\text { There is a certain show, play, or film Y available to watch for X. } \\
\text { X is a sentient individual capable of watching Y. } \\
\text { Y carries a certain message, some information, or a meaning } \\
\text { that can be internalized or understood by X. } \\
\text { X wants to see Y. } \\
(\ldots)\end{array}$ \\
\hline \multirow{3}{*}{ 2. The Core } & $\begin{array}{l}\text { X comes into visual contact with Y. } \\
\text { X visually perceives (sees) Y. } \\
\text { X engages in watching Y. } \\
\text { X terminates watching Y. }\end{array}$ \\
\hline 3. The Effects & $\begin{array}{l}\text { X has internalized or understood the message, information, } \\
\text { or meaning carried by Y. } \\
\text { X has the experience of watching Y. }\end{array}$ \\
\hline
\end{tabular}


The Watching Scenario

$\mathrm{X}$ shares his/her experience of $\mathrm{Y}$ with other individuals.

(...)

The SAS of watching a show, play, film, or similar spectator event requires the event $(\mathrm{Y})$ being the object of visual perception for a sentient human individual $(\mathrm{X}) . \mathrm{Y}$ is assumed to carry a certain kind of message, information, or meaning that $\mathrm{X}$ is able and willing to decode and internalize or understand. Moreover, the individual must be willing to watch the event and undertake steps to do so. The "(...)" marking in the Before stage is meant to represent any further unspecified preparatory conditions necessary for the scenario to take place, such as the need of the spectator to possess the mental or physical capacity to engage in the act of watching, or the lack of impeding forces or circumstances preventing the individual from taking part in the activity. The Core of the scenario requires $\mathrm{X}$ coming into visual contact with $\mathrm{Y}$, followed by the visual perception of the spectator event. $\mathrm{X}$ must, subsequently, engage in the act of watching by voluntarily paying attention to $\mathrm{Y}$ over a period of time. Watching implies, thus, the act of volition on the part of the spectator. The Core of the scenario is concluded with eventual termination of the watching experience. Numerous elements of the Effects may include X's having internalized or understood the information carried by $\mathrm{Y}$, as well as having the experience of watching Y. Finally, the non-necessary consequences of the scenario (the After stage) may include, among numerous unspecified others, the spectator sharing the experience with other individuals.

I believe that the script presented in Table 3 is sufficiently representative of the Watching Scenario underlying the metonymic shift exemplified by (14), (20), and (21). In those cases, the Core stage of $\mathrm{X}$ visually perceiving (seeing) $\mathrm{Y}$ stands for the whole Watching Scenario (PART FOR WHOLE metonymy).

Apart from the Watching Scenario, similar scripts may be proposed for other categories presented by Bierwiaczonek (2013: 201-202) in order to illustrate PART FOR WHOLE metonymic mappings within their respective SASs. In all of them, the act of visual perception metonymically stands for the whole respective script.

Consider, by way of illustration, sentences (15), (22), and (23), which refer to a particular Visiting Scenario encompassing a patient's appointment at a doctor's office in order to receive medical attention. Unavoidably, the act of visual perception of the doctor by the patient (and of the patient by the doctor) is a salient stage of the script allowing for the PART FOR WHOLE metonymic shift. It is important to note at this point that a feasible description of different examples from the dictionary database may require their underlying scenarios to be appropriately adjusted and modified.

For instance, other kinds of visits may require distinct variations of the Visiting Scenario. Consider the following: 
32. I will be seeing her tomorrow night. (LDCE)

33. I saw Jane while I was out. (LDCE)

34. I don't know who he is, but I've seen him around. (LDCE)

Sentences (32) to (34) refer to visiting or meeting a person, presumably for personal rather than medical or business-related purposes. The act of visual perception remains a salient stage of the script, but other elements of the scenario would have to be adequately modified for a comprehensive representation of the metonymic transfer. Note also that it is possible to use the verb see to metonymically stand for visiting a place or location rather than a person, as shown below:

35. I would like to see Alaska. (TNODE)

36. I want to see something of those countries. (TNODE)

37. Would you like to see round the house? (LDCE)

Sentences (35) and (36) refer to the scenario of travelling or visiting places in the sense of undertaking a recreational or touristic activity, but the context of sentence (37) is different and may involve either a meeting for personal purposes or a commercial activity in which visitors inspect a house they intend to rent or purchase. Thus, (35) and (36) would conceivably require a different variation of a SAS than (37) in order for their respective PART FOR WHOLE metonymic shifts to be illustrated.

The analysis of the dictionary database suggests also that the Checking and Controlling Scenario, underlying examples (19), (30), and (31), may have a number of varieties. For instance, certain scripts of Checking and Controlling involve a strong willingness to help or assist a person, thus possessing the illocutionary force of promises or offers to perform a particular activity (commissives):

38. Leave the papers with me and I'll see what I can do. (LDCE)

39. I must see about selling the house. (CCALED)

40. I'll see to Dad's tea. (TNODE)

Other examples may be used to oblige the addressee to perform an activity, thus possessing the illocutionary value of directives:

41. You should get that tooth seen to by the dentist. (LDCE)

Another variation involves the speaker's making sure that a person is adequately rewarded for an action or behaviour, as in (42), below: 
42. Just do this for me and I will see you right. (LDCE)

It seems safe to assume, therefore, that different categories of PART FOR WHOLE metonymies discussed by Bierwiaczonek (2013: 201-202) exhibit a degree of flexibility. In those examples, the English verb see may metonymically stand for different realisations of complex SASs of which the stage of visual perception is a particular cognitively salient part.

One common metonymic category that is not discussed by Bierwiaczonek (2013: 201-202) is the use of see in the sense of accompanying somebody to a location:

43. My mother used to see me across the road. (LDCE)

44. Let me see you to the door. (LDCE)

45. He didn't offer to see her to her car. (CCALED)

46. They've gone to the airport to see their son off. (LDCE)

47. Security guards saw him off the premises. (LDCE)

I believe that such examples are instances of the PART FOR WHOLE metonymy relying on the Accompanying Scenario, as demonstrated in Table 4:

Table 4. The Accompanying Scenario

\begin{tabular}{|c|c|}
\hline \multicolumn{2}{|r|}{ The Accompanying Scenario } \\
\hline 1. The Before & $\begin{array}{l}\text { There is an individual }(\mathrm{Y}) \text { who needs to be physically } \\
\text { accompanied to a location (L). } \\
\text { X is an individual capable of physically accompanying } \\
\text { Y to L. } \\
\text { - } \quad \mathrm{X} \text { intends to accompany Y to L. }\end{array}$ \\
\hline 2. The Core & $\begin{array}{l}\text { - } \mathrm{X} \text { and } \mathrm{Y} \text { embark on their journey to } \mathrm{L} \text {. } \\
\text { - } \mathrm{X} \text { and } \mathrm{Y} \text { arrive at } \mathrm{L} \text {. } \\
\text { - } \mathrm{X} \text { perceives (sees) that } \mathrm{Y} \text { is at } \mathrm{L} \text {. } \\
\text { - } \quad \mathrm{X} \text { terminaterstands that } \mathrm{Y} \text { is at } \mathrm{L} \text {. } \\
\end{array}$ \\
\hline 3. The Effects & - $\quad \mathrm{Y}$ is at $\mathrm{L}$. \\
\hline 4. The After & $\begin{array}{l}\text { - X goes back to his/her previous location. } \\
(\ldots)\end{array}$ \\
\hline
\end{tabular}

The Accompanying Scenario requires two sentient individuals (X) and (Y), and Y needs to be accompanied to a location $(\mathrm{L})$. $\mathrm{X}$, who is capable of accompanying $\mathrm{Y}$ and willing to do so, embarks on the journey and successfully arrives with Y at L. Consequently, 
$\mathrm{X}$ visually perceives $\mathrm{Y}$ at $\mathrm{L}$ and understands this fact. $\mathrm{X}$ then terminates accompanying $\mathrm{Y}$ to $\mathrm{L}$ and may, in some cases, return to their previous location (the After stage).

In the Accompanying Scenario, it is the stage of $\mathrm{X}$ visually perceiving $\mathrm{Y}$ at location $\mathrm{L}$ that is used to metonymically access the Accompanying Scenario. It is important to note, however, that although sentences (43) to (46) possess clear metonymic qualities of physically accompanying a person to a location, sentence (47) is ambiguous because seeing off may refer either to physically accompanying an unwanted visitor off the premises or to repelling an individual from trespassing due to the sheer presence of security guards. Such examples would require the study of metonymy-metaphor interplay for their explanation. This problem will be briefly addressed in the following section.

Another PART FOR WHOLE metonymy found in the database is illustrated by the following examples:

48. We saw in Chapter 16 how annual cash budgets are produced. (CCALED)

49. Elements are usually classified as metals or non-metals (see Chapter 11). (TNODE)

50. See below/above. (LDCE)

The referential use of see, as presented above, is typical of formal written registers, such as instruction manuals or academic papers. The verb of visual perception in this context stands for referring to another part of the text in order to retrieve or check important information. Note, that in sentences (48) to (50), see does not stand solely for the act of visually perceiving the appropriate part of the text; rather, it stands for the whole sequence of events required for looking up the relevant information, including searching for and retrieving the appropriate portion of the text, reading it, and understanding it. Thus, I consider (48) to (50) to be yet another category of PART FOR WHOLE metonymy in which the act of visual perception is a salient stage of the script, and it is this stage that provides mental access to the whole SAS.

To conclude the discussion of PART FOR WHOLE prepositional metonymy patterns, consider the following database examples:

51. I can see you're not happy with the situation. (LDCE)

52. After a month's practice, you should see a difference in your playing. (LDCE)

53. She went outside to see what was happening. (LDCE)

In sentences (51) to (53), see is used in the sense of learning or comprehending a certain phenomenon. Note that in such examples, acquiring appropriate knowledge happens as a direct result of visually perceiving the phenomenon. This is hardly surprising because, as Sweetser (1990: 33-35) notes, physical vision is a primary source 
of information. Seeing, thus, appears to be a core component of acquiring knowledge in this context. To illustrate that, consider the following Learning Scenario:

Table 5. The Learning Scenario

\begin{tabular}{|l|l|}
\hline \multicolumn{2}{|c|}{ The Learning Scenario } \\
\hline 1. The Before & $\begin{array}{l}\text { There is a certain proposition, message, sign, or piece } \\
\text { of information Y, the knowledge of which is important to X } \\
\text { in a given context. } \\
\text { X is a sentient individual capable of acquiring knowledge of Y. } \\
\text { X intends to acquire knowledge of Y. } \\
\text { X is unimpeded in his/her acquisition of knowledge of Y. } \\
(\ldots)\end{array}$ \\
\hline 2. The Core & $\begin{array}{l}\text { X comes in contact with Y. } \\
\text { X visually perceives (sees) Y. } \\
\text { X acquires the knowledge of Y. } \\
(\ldots)\end{array}$ \\
\hline 3. The Effects & $\begin{array}{l}\text { X has acquired the knowledge of Y. } \\
(\ldots)\end{array}$ \\
\hline 4. The After & $\begin{array}{l}\text { X further expands his/her knowledge of Y. } \\
(\ldots)\end{array}$ \\
\hline
\end{tabular}

It is well beyond the scope of this paper to adequately account for different sets of conditions and circumstances applicable to the processes of learning and acquiring information. Thus, the Learning Scenario presented above unavoidably constitutes significant idealization and oversimplification of these processes. However, I believe the script presented in Table 5 is sufficiently representative of the metonymic shift that underlies database examples (51) to (53). In the scenario, a sentient human being $\mathrm{X}$ comes into visual contact with the object of learning $\mathrm{Y}$. The knowledge of $\mathrm{Y}$ is important for $\mathrm{X}$ in a given context, and $\mathrm{X}$ is unimpeded in the attempt to learn $\mathrm{Y}$. As a result of coming into contact with Y, X visually perceives $\mathrm{Y}$. Since visual perception is a primary channel of learning, $\mathrm{X}$ acquires appropriate knowledge of $\mathrm{Y}$ as a result of the encounter. The Effect of the scenario includes $\mathrm{X}$ possessing the knowledge of Y. The After stage may be realised, for example, by $\mathrm{X}$ expanding the knowledge further for other purposes and future goals.

In the Learning Scenario, the act of visual perception is a central component of the script for acquiring information by a sentient human being. Thus, sentences (51) to (53) may be characterised as PART FOR WHOLE propositional metonymy. Note, however, that this interpretation is possible only in cases where the effect of acquiring appropriate knowledge of $Y$ takes place as a result of X's direct visual contact with $\mathrm{Y}$ and where $\mathrm{X}$ 's visual perception of $\mathrm{Y}$ is necessary for the acquisition of knowledge. 
However, in the dictionary database, there are numerous instances where seeing is related to learning and acquiring information without the direct mediation of visual perception. Consider the following examples:

54. These chocolates are gorgeous. Try some and see for yourself. (LDCE)

55. I will call him and see how the job interview went. (LDCE)

56. I saw through his excuses. (LDCE)

Sentences (54) to (56) cannot be convincingly analysed in the light of the Learning Scenario because the central stage of the script, the visual perception of the object of learning, is not a necessary condition for acquiring appropriate information in this context. In fact, other sensory modalities might be more prominently involved. In (54), the relevant information is obtained primarily through the sense of taste and in (55) through the sense of hearing. On the other hand, sentence (56) refers to the Speaker's processes of thinking and mental deduction, through which a particular conclusion about a third party is reached. Therefore, what appears to be the case with the use of see in (54) to (56) is a more conceptually distant inter-domain mapping. In order to analyse such samples in a convincing way, it is important to consider the role of metaphors or, more precisely, the role of metonymy-metaphor interaction in conceptualising the link between visual perception and intellectual comprehension.

\section{KNOWING IS SEEING: a case of metaphor-metonymy interaction}

The metaphoric link between understanding and seeing was explicitly proposed by Lakoff and Johnson (1980: 48):

57. I see what you're saying.

58. It looks different from my point of view.

59. What is your outlook on that?

60. I view it differently.

Lakoff and Johnson (1999: 354-355) elaborate on that by positing that the KNOWING IS SEEING metaphor constitutes the basis of the folk theory of how the mind functions. They also point to the ubiquitous and cross-linguistic nature of the metaphor and its pervasiveness in influencing the intellectual tradition of Western culture:

61. I see what you mean.

62. Could you shed some light on the chaos theory for me?

63. I have a great deal of insight into social relations. 
64. That's about as obscure an idea as l've ever seen.

65. We just can't seem to get clear about gender roles.

66. Talk about a murky argument.

The dictionary database analysis of the verb see reveals numerous examples in which theverbisusedinthesense of mentalexperiencingorintellectualapprehension ofacertain phenomenon for which no direct mediation of the visual component is necessary. Such samples include, apart from the ones presented above in (54) to (56), the following ones:

67. I saw through your little ruse from the start. (CCALED)

68. You see, the thing is, I'm really busy right now. (LDCE)

69. The other officers laughed, but Nichols couldn't see the joke. (LDCE)

70. They are unimpressed with the scheme and rightly see it for what it is. (LDCE)

71. Now I see that I was wrong. (CCALED)

72. You and I see things differently. (TNODE)

In order to account for such instances, in this section I intend to focus on the link between visual perception and intellectual comprehension in more detail. Although I agree that the relationship is metaphoric in nature, I believe that the situation is somewhat more complex than a simple cross-domain mapping and that for a more comprehensive understanding of the issue, the role of metonymic mappings and metaphors must be considered simultaneously.

In order to demonstrate that, it is important to mention Grady's (1999) distinction between resemblance metaphors and correlation metaphors. Resemblance metaphors result from a perceived similarity between elements of the source domain and target domain, as in Achilles is a lion, where the feature of courage is canonically ascribed to the animal and mapped onto the human character. Correlation metaphors, on the other hand, arise as a result of the correlation of two domains in human experience. KNOWING IS SEEING is an example of this kind of metaphor. In other words, the metaphoric transfer between visual perception and intellectual comprehension is based on the correlation of those elements in the human experience of acquiring knowledge. The nature of this correlation was, at least partly, presented in Table 5. As demonstrated in the Learning Scenario, visual perception, due to its status as a primary source of knowledge, may be considered a core element of the script for learning by means of visual perception (PART FOR WHOLE propositional metonymy).

Observations like the one above pose serious questions concerning the relation between correlation metaphors and metonymy. This problem has sparked a considerable debate in contemporary linguistics (c.f. Barcelona 2000; Grady \& Johnson 2002; Kövecses 2010, 2013; Kövecses \& Radden 1998; Radden 2002; Radden \& Kövecses 1999), 
and it is well beyond the scope of this paper to address it in any detail. Suffice it to say here that there appears to be compelling evidence that metonymic processes play a role in the emergence of certain metaphoric patterns. Kövecses (2013), for instance, claims that most correlation metaphors derive through the metonymic stage via the processes of schematization and generalization. Such is the case with understanding and seeing, which were originally a part of the same conceptual structure (metonymic relation) but have been abstracted into the metaphoric pattern linking visual perception and intellectual comprehension (Kövecses 2013: pp. 81-83). Therefore, in order to have a slightly more comprehensive understanding of the KNOWING IS SEEING metaphor, it is important to look in more detail at different patterns of metonymy-metaphor interaction in which the emergent metaphor is based on a metonymic mapping.

A study of interaction between metaphor and metonymy for linguistic expressions in English was first proposed by Goossens (1990/2002), who coined the term "metaphtonymy" as an umbrella term for such processes. When analysing his language data, Goossens (1990/2002: 355-357) identifies different instances of metaphor and metonymy, as in (73) and (74), below:

73. She barked at me and hung up.

74. 'Oh, dear,' she giggled, 'I'd quite forgotten.'

Sentence (73) may be classified as an example of "pure" metaphor, due to the crossdomain transfer between animal vocalisation and human sound. Sentence (74), on the other hand, possesses a metonymic reading in which the speaker may have uttered specific words while giggling. In such a case, (74) represents PART FOR WHOLE metonymy, wherein giggling is a part of the actual human vocalisation. Another interpretation is also possible for sentence (74), however, namely one in which the speaker may have uttered the words as if she were giggling (i.e., in a light-hearted, perhaps slightly silly manner). In such a case, there is a metaphoric transfer between the domains of non-verbal vocalisation and human speech. However, the conceptual link with the metonymic reading is still present there, because the kind of speech exemplified by (74) is characterised precisely by light-heartedness and silliness and may even possess some physical qualities of giggling. Goossens (1990/2002) calls such examples "metaphor from metonymy", that is, cases of metaphoric transfer that result from and are motivated by metonymic relations and in which the metonymic reading may still be present as a possible interpretation of the utterance.

Goossens's approach has been reviewed and refined by Ruiz de Mendoza and his collaborators (Ruiz de Mendoza 2000; Ruiz de Mendoza \& Díez Velasco 2002; Ruiz de Mendoza \& Otal Campo 2002). They claim that Goossens's metaphor from metonymy category can be characterised more precisely as an instance of a metonymic domain 
expansion within the source of the metaphoric mapping. By way of illustration, consider Ruiz de Mendoza and Díez Velasco's (2002: 518-520) analysis of to beat one's breast.

This metaphoric expression is commonly used to designate an act of the open show of sorrow about a certain situation. It is based on the physical act of beating one's breast, which metonymically stands for the whole, religiously motivated, scenario of showing sorrow. The activity of striking one's chest area is a cognitively salient part of this script. Thus, such a metonymic shift may be considered, in accordance with the discussion of the SASs in the preceding section, an instance of the PART FOR WHOLE propositional metonymy, although Ruiz de Mendoza and Díez Velasco (2002) refer in this context to the phenomenon of domain expansion. The metonymic target is used, subsequently, to metaphorically access the target domain in which the open show of sorrow, which may in fact be a disingenuous act carried out in order to achieve one's particular goals, is realised without the physical act of beating one's breast:

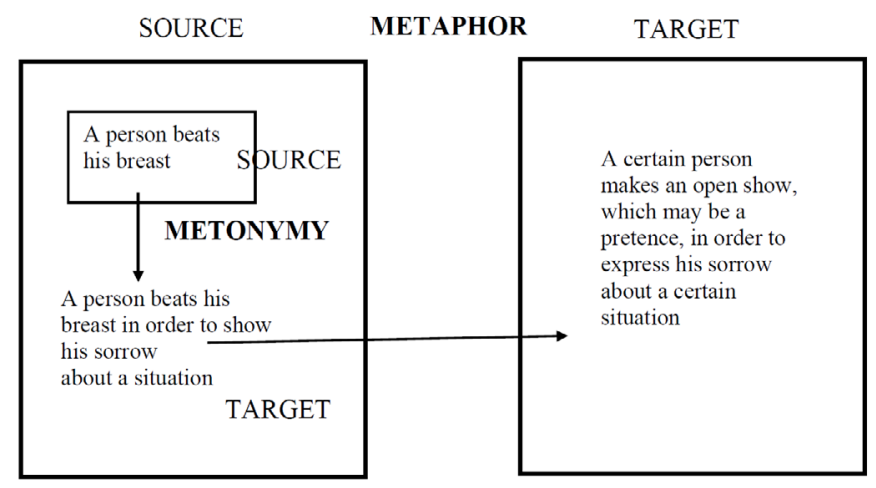

Figure 1. To beat one’s breast (Ruiz de Mendoza \& Díez Velasco 2002: 519)

I believe that a similar line of enquiry may plausibly be applied for the analysis of the KNOWING IS SEEING metaphor, as exemplified in (54) to (56) and (67) to (72). Consider the following diagram, where $\mathrm{X}$ is a sentient human being and $\mathrm{Y}$ stands for the object of learning, that is, any kind of proposition, message, sign, or piece of information the knowledge of which is important for $\mathrm{X}$ in a given context:

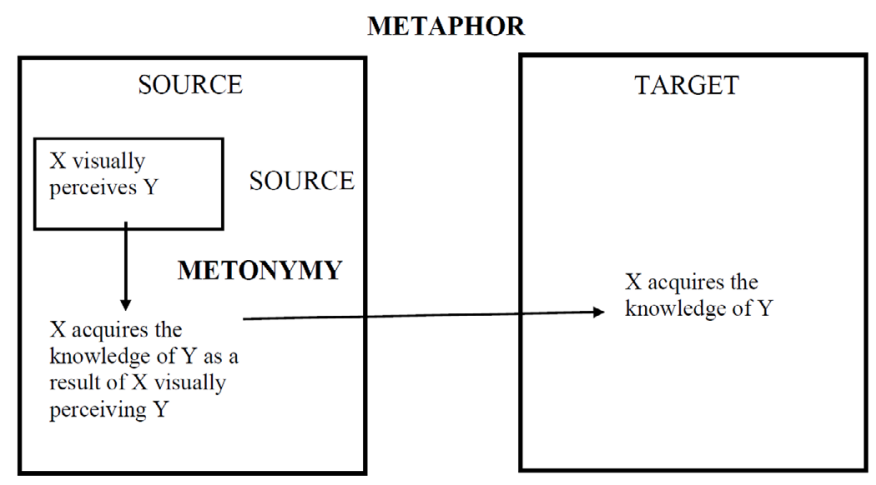

Figure 2. KNOWING IS SEEING metaphor 
The diagram shown in Figure 2, despite its unavoidable oversimplifications, appears to be reasonably sufficient for the purpose of presenting the basic structure of the KNOWING IS SEEING metaphoric pattern. The metaphor is based on a sentient human being's (X's) visual perception of the object of learning $(\mathrm{Y})$, which metonymically stands for the whole scenario of acquiring the knowledge of $\mathrm{Y}$ as a result of $\mathrm{X}$ visually perceiving Y. Note at this point that this metonymic shift is congruent with the metonymic pattern shown in (51) to (53) and may plausibly be analysed as a PART FOR WHOLE propositional metonymic mapping within the Learning Scenario, as demonstrated in Table 5, above. The target of the metonymic shift is subsequently used to metaphorically access the target domain, which includes $\mathrm{X}$ acquiring knowledge of $\mathrm{Y}$ without the direct mediation of visual perception, as exemplified in (54) to (56) and (67) to (72).

Finally, an interesting side note to consider is provided by database examples that may be ambiguous between metonymic and metaphoric reading. Consider the following:

75. A lot of people saw what was happening but did nothing about it. (CCALED)

76. I see from your appraisal report that you have asked for retraining. (TNODE)

77. Let me just see what the next song is. (CCALED)

In such cases, depending on the context of the utterance, the relevant knowledge may be acquired as a direct result of visual perception or without the mediation of visual input. In sentence (75), the future prediction to which the speaker is referring may have been based on direct visual observation or may have come as a result of mental deduction. Sample (76) describes an appraisal report in which the need for retraining may have been explicitly stated or implicitly hinted at and successfully deduced by one's superior. Similarly, in sentence (77), the act of checking what song is forthcoming may involve direct visual observation of the display of a player device. Alternatively, checking the appropriate track may involve the sense of hearing or, possibly, the speaker's mental capacities of memory and reasoning. In all of the above cases, the reading requiring direct visual perception warrants the metonymic interpretation of the utterance of the PART FOR WHOLE kind, as exemplified in (51) to (53). In cases where no visual input is directly required, metaphoric interpretation is enforced, in accordance with Figure 2 and examples (54) to (56) and (67) to (72). This observation sheds extra light on the discussion of metonymymetaphor interaction and suggests the possibility of other cases that may plausibly be explained as borderline instances residing on a metonymy-metaphor continuum.

\section{Conclusions}

English verbs of sensory perception appear to be significant generators of numerous polysemous senses. The aim of this paper was to propose a cursory analysis of certain polysemy patterns of the verb see in the light of propositional metonymy 
theory. In order to achieve this, a data sample study based on three distinct dictionary sources was conducted. The sense of involuntary visual perception was established as the basic non-metonymic meaning of the term. The dictionary sources were subsequently analysed in order to distinguish different extensions of see that might be motivated by metonymic mappings.

The analysis suggests that the English verb of visual perception constitutes a significant generator of divergent metonymic senses. Such meaning extensions may feasibly be discussed in the light of propositional metonymy theory as presented by Bierwiaczonek (2013). In accordance with Panther and Thornburg (1999), different metonymic extensions are analysed by means of specific context-dependent SASs, of which the stage of visual perception is a cognitively salient part. The most significant metonymic category appears to be the PART FOR WHOLE propositional mapping. It contains the cases in which the stage of visual perception (part of the Core of a SAS) stands for the whole relevant scenario. This category includes conceptual patterns described by Bierwiaczonek (2013: 201-202), as well as others (e.g., different metonymic shifts motivated by the Accompanying Scenario). In order to account for different database samples, the relevant SASs must possess a degree of flexibility, allowing for variation of their constituent elements.

Another particularly productive conceptual link in English is the one in which the verb see is used in the sense of acquiring appropriate information or knowledge. The conceptual link between visual perception and intellectual comprehension has posed some theoretical challenges. In contemporary linguistics, the relationship is predominantly considered to be metaphoric in nature (c.f. Kövecses 2013: 81-83; Lakoff \& Johnson 1980: 48, 1999: 354-355; Sweetser 1990: 33-35). However, there appears to be compelling evidence that for a more comprehensive understanding of the phenomenon, the role of metonymic mappings must be considered alongside metaphor. In accordance with Ruiz de Mendoza and Díez Velasco (2000: 518-519), I consider KNOWING IS SEEING a case of metonymic expansion within the source of the metaphoric mapping. The metonymic relation is congruent with the propositional PART FOR WHOLE metonymic shift within the Learning Scenario presented in Table 5, and can plausibly account for cases where acquiring appropriate knowledge happens as a direct result of the visual perception of the object of learning. The metaphoric mapping, on the other hand, accounts for cases where acquiring information happens without the requirement of direct visual input, as discussed in Figure 2 and exemplified by samples (54) to (56) and (67) to (72). Certain database samples may be ambiguous, and, depending on the context, their interpretation may gravitate towards either metonymic reading or metaphoric reading.

Although the present paper discusses certain patterns of metonymic extensions of see in English and briefly touches upon the problems of metonymy-metaphor interaction in relation to the English verb of visual perception, the analysis of these issues is by 
no means complete and leaves considerable space for further investigation. Firstly, the analysis proposed in this paper is based on a considerably limited pool of dictionary data. The data samples include predominantly well-established polysemy patterns of the English verb of visual perception as they are presented and recorded in three dictionary sources. Although this has allowed for the representation of a number of common meaning extensions of see, it does not allow for a comprehensive representation of the polysemy network pertaining to the verb. A more comprehensive study of the English verb of visual perception would require much richer and more informative data, presumably based on a more detailed analysis of corpora sources.

Secondly, an elaborate sample database would unavoidably require a more complex theoretical background in order for an adequate description of the issues at hand to be provided. Although the propositional theory of metonymy and the notion of SASs appear to be reasonably adequate tools for the description of the majority of data samples, future research might undoubtedly benefit from the use of more detailed and representative SASs underlying their respective language samples. Also, because of the limited scope of this paper, the database analysis carried out above largely ignores the possibility of PART FOR WHOLE metonymic mappings within SASs. Although the relationship between visual perception and intellectual comprehension was identified in the present paper as a case of metonymic expansion within the source of metaphoric mapping, a more comprehensive study of see would require the investigation of different patterns of interaction between metaphor and metonymy. A more comprehensive account of the English verb of visual perception would thus require a more detailed focus on the problem of propositional metonymy, correlation metaphors, and metaphor-metonymy interaction for the discussion of different polysemy patterns of the verb.

Thirdly, see is not the only verb of visual perception in English, and a more representative study of the issues at hand would require the consideration of other terms, such as observe, notice, perceive, view, and discern. This would have to be connected with a more detailed enquiry into numerous idiomatic expressions referring to the human visual modality. It may also be interesting to see what kinds of metonymy and metaphor are at work there and how they interact in the formulation of such expressions. A more comprehensive analysis of a richer pool of language data could possibly allow for the formulation of a complex semantic model pertaining to English expressions of visual perception. It is hoped, therefore, that the present paper may serve as a small step in this direction and that further studies will continue such enquiries in a more systematic way for the aim of a more comprehensive account of linguistic representation of visual perception expressions in English. 


\section{References}

Bierwiaczonek, B. 2001. Implikatury jako metonimie, czyli o poznawczych podstawach pragmatyki. In: W. Kubiński \& D. Stanulewicz (eds.), Językoznawstwo kognitywne II. Zjawiska pragmatyczne, 95-115. Gdańsk: Wydawnictwo Uniwersytetu Gdańskiego.

Bierwiaczonek, B. 2007. On formal metonymy. In: K. Kosecki (ed.), Perspectives on Metonymy: Proceedings of the International Conference "Perspectives on Metonymy", Held in Łódź, Poland, May 6-7, 2005, 43-67. Frankfurt am Main: Peter Lang.

Bierwiaczonek, B. 2013. Metonymy in Language, Thought and Brain. Sheffield: Equinox. Barcelona, A. 2000. On the plausibility of claiming a metonymic motivation for conceptual metaphor. In: A. Barcelona (ed.), Metaphor and Metonymy at the Crossroads, 32-58. Berlin: Mouton de Gruyter.

Croft, W. 1993. The role of domains in the interpretation of metaphors and metonymies. Cognitive Linguistics 4: 335-370.

Goossens, L. 1990 [2002]. Metaphtonymy: the interaction of metaphor and metonymy in expressions for linguistic action. Cognitive Linguistics 3(1): 323-40. Reprinted in: R. Dirven \& R. Pörings (eds.), Metaphor and Metonymy in Comparison and Contrast, 349378. Berlin/New York: Mouton de Gruyter.

Grady, J. 1999. A typology for motivation for conceptual metaphor. In: R. Gibbs and G. Steen (eds.), Metaphor in Cognitive Linguistics, 79-100. Amsterdam: John Benjamins.

Grady, J. \& Johnson, C. 2002. Converging evidence for the notion of substance and primary scene. In: R. Dirven and R. Pörings (eds.), Metaphor and Metonymy in Comparison and Contrast, 533-554. Berlin/New York: Mouton de Gruyter.

Hernández, L. 2007. High-level metonymies in the understanding of modality: a crosslinguistic analysis. In K. Kosecki (ed.), Perspectives on Metonymy: Proceedings of the International Conference "Perspectives on Metonymy", Held in Łódź, Poland, May 6-7, 2005, 133-146. Frankfurt am Main: Peter Lang.

Kövecses, Z. 2010. Metaphor: A Practical Introduction. 2nd ed. Oxford: Oxford University Press.

Kövecses, Z. 2013. The metaphor-metonymy relationship: correlation metaphors are based on metonymy. Metaphor and Symbol 28: 75-88.

Kövecses, Z. \& Radden, G. (1998). Metonymy: developing a cognitive linguistic view. Cognitive Linguistics 9: 37-77.

Lakoff, G. 1987. Women, Fire and Dangerous Things: What Categories Reveal about the Mind. Chicago: University of Chicago Press.

Lakoff, G. \& Johnson, M. 1980. Metaphors We Live By. Chicago: University of Chicago Press.

Lakoff, G. \& Johnson, M. 1999. Philosophy in the Flesh. New York: Basic Books.

Miller, G. A. \& Johnson-Laird, P. N. 1976. Language and Perception. Cambridge, Massachusetts: Harvard University Press. 
Norrick, N. R. 1981. Semiotic Principles in Sematic Theory. Amsterdam: John Benjamins. Nunberg, G. 1978. The Pragmatics of Reference. Indiana University Linguistics.

Panther, K.-U. \& Thornburg, L. 1999. The potentiality for actuality metonymy in English and Hungarian. In: K.-U. Panther \& G. Radden (eds.), Metonymy in Language and Thought, 303-332. Amsterdam/ Philadelphia: John Benjamins.

Panther, K.-U. \& Thornburg, L. 2003a. Introduction: on the nature of conceptual metonymy. In: K.-U. Panther \& L. Thornburg (eds.), Metonymy in Pragmatic Inferencing, 1-20. Amsterdam/Philadelphia: John Benjamins.

Panther, K.-U. \& Thornburg, L. 2003b. Metonymies as natural inference and activation schemas: the case of dependent clauses as independent speech acts. In: K.-U. Panther and L. Thornburg (eds.), Metonymy in Pragmatic Inferencing, 127-147. Amsterdam/ Philadelphia: John Benjamins.

Panther, K.-U. \& Thornburg, L. 2003c. The roles of metaphor and metonymy in English - er nominals. In: R. Dirven and R. Pörings (eds.), Metaphor and Metonymy in Comparison and Contrast, 279-319. Berlin/New York: Mouton de Gruyter.

Panther, K.-U. \& Thornburg, L. 2005. Inference in the construction of meaning: the role of conceptual metonymy. In: E. Górska and G. Radden (eds.), Metonymy-Metaphor Collage, 37-57. Warsaw: Wydawnictwo Uniwersytetu Warszawskiego.

Panther, K.-U. \& Thornburg, L. 2007. Metonymy. In: D. Geeraerts and H. Cuyckens (eds.), The Oxford Handbook of Cognitive Linguistics, 236-263. Oxford: Oxford University Press.

Radden, G. 2002. How metonymic are metaphors? In: R. Dirven and R. Pörings (eds.), Metaphor and Metonymy in Comparison and Contrast, 407-433. Berlin/New York: Mouton de Gruyter.

Radden, G. \& Kövecses, Z. 1999. Towards a theory of metonymy. In K.-U. Panther and G. Radden (eds.), Metonymy in Language and Thought, 17-59. Amsterdam/Philadelphia: John Benjamins.

Ruiz de Mendoza, F. J. 2000. The role of mappings and domains in understanding metonymy. In A. Barcelona (ed.), Metonymy and Metaphor at the Crossroads, 109-132. Berlin/ New York: Mouton de Gruyter.

Ruiz de Mendoza, F. J. \& Otal Campo, J. L. 2002. Metonymy, Grammar, and Communication. Albolote, Spain: Editorial Comares.

Ruiz de Mendoza, F. J. \& Díez Velasco, O. I. 2002. Patterns of conceptual interaction. In R. Dirven and R. Pörings (eds.), Metaphor and Metonymy in Comparison and Contrast, 489-532. Berlin/New York: Mouton de Gruyter.

Sweetser, E. 1990. From Etymology to Pragmatics: Metaphorical and Cultural Aspects of Semantic Structure. Cambridge: Cambridge University Press.

\section{Dictionary sources}

Longman Dictionary of Contemporary English. 2005. 4th ed. Harlow: Longman. 
The New Oxford Dictionary of English. 1998. Oxford: Clarendon Press.

Collins COBUILD Advanced Learners' English Dictionary. 2005. 4th ed. Kraków: Express Publishing.

$$
* * *
$$

Lukasz Matusz holds a $\mathrm{PhD}$ degree in linguistics from the University of Silesia in Katowice. He is currently employed as an Assistant Professor at the Institute of Linguistics of the University of Silesia. His research interests include the cognitive theory of metaphor and metonymy, as well as language taboo and the linguistic reality of swearing. 